\title{
Effect of Trace Ce/La Addition on the Microstructure and Microhardness of Nanostructured Nickel-based Superalloy Inconel 718
}

\author{
H. M. Medrano-Prieto ${ }^{1}$, C.G. Garay-Reyes ${ }^{2}$, M.A. Ruiz-Esparza-Rodriguez ${ }^{2}$, I. Estrada-Guel ${ }^{2}$, J.M. \\ Silva-Aceves $^{1}$, J.S. Castro-Carmona ${ }^{1}$, H. Camacho-Montes ${ }^{1}$ and R. Martínez-Sánchez ${ }^{2}$. \\ ${ }^{1}$ Universidad Autónoma de Ciudad Juárez (UACJ), Ciudad Juárez, México. \\ ${ }^{2}$ Centro de Investigación en Materiales Avanzados (CIMAV), Laboratorio Nacional de Nanotecnología, \\ Chihuahua, México.
}

The nickel-base superalloy Inconel 718, have excellent properties to be used in high temperature applications, its principal characteristics are: high resistance to oxidation, good mechanical properties in elevated work temperatures, owing of that the principal applications are in parts of aeronautic and aerospace engines [1-2]. During the last two decades, research on the effects of rare earths in superalloys has made significant progress. The use of elements like rhenium, hafnium, tantalum, niobium, ruthenium among others has increased, due to the need to obtain superalloys with properties superior to the current ones. It has been reported that some rare earth elements such as yttrium and cerium have positive effects both in the hardening mechanism by solid solution. This due to an increase in the lattice mismatch, as in the grain limit, and modification of carbides and eutectic phases; which significantly improves the properties of these alloys at elevated temperatures. Yttrium has been applied successfully in many fields of research such as metallurgy, chemistry and surface engineering. However, the use of cerium / lanthanum in superalloys has not been satisfactorily explored although studies indicate that they are elements with high potential for the improvement of mechanical and microstructural properties [3].

The nanostructured Inconel 718 modified with traces $\mathrm{Ce} / \mathrm{La}$ addition was processed by mechanical alloying (MA). The Inconel 718 alloy used was a commercial alloy and the mixture of rare earths $(\mathrm{Ce} / \mathrm{La}$ $-50 / 50$ ) was taken with a purity of $99 \%$ to form alloys modified with contents of $0.1,0.2$ and $0.3 \mathrm{wt} \%$ of $\mathrm{Ce} / \mathrm{La} .5 \mathrm{~h}$ of milling time in a high-energy mill Spex 8000 was used to fabricate alloys. The milling device and milling media used were made from hardened steel. All millings runs were performed with $\mathrm{N}$-heptane as process control agent and argon was used as inert milling atmosphere. Powder mass $8.5 \mathrm{~g}$ and a ball-to-powder ratio of 5:1 were used. The compaction of the powders was carried out by means of a hydraulic press under a compaction pressure of $1.56 \mathrm{GPa}$ for 5 minutes. The sintering process was maintained at $1300{ }^{\circ} \mathrm{C}$ for $3 \mathrm{~h}$ in vacuum sealed quartz ampoules. The structural and microstructural characterization was carried out by a Panalytical X'Pert PRO x-ray diffractometer, scanning electron microscope HITACHI SU3500 and Vickers microhardness was evaluated in LM300 AT tester.

The Fig. 1 present the SEM-BSE micrographs of the Inconel 718 and those with Ce/La, these micrographs illustrate the presence of acicular phases and particles with rounded morphologies homogeneously distributed. The typical microstructure of Inconel 718 corresponds to a homogeneous and refined microstructure composed for oxides, carbides and $\delta$-precipitates $\left(\mathrm{Ni}_{3} \mathrm{Nb}\right)$ with acicular morphology. In the micrographs is observed that higher amounts of $\mathrm{Ce} / \mathrm{La}$ content favor the mayor refinement of the rounded particles. In the graph corresponding to Fig. 2 is observed that the Ce/La additions in the Inconel 718 favors the increments in HV values in sintered, solubilized and aged conditions. The peaks of hardness are obtained in Inconel 718 with $0.2 \mathrm{Ce} / \mathrm{La}$ (wt. \%). 
References:

[1] H.F. Merrick, Met. Trans. A, 7A (1995) p. 505.

[2] G. Appa Rao, M. Srinivas and D.S. Sarma, Mater. Sci. Eng. A, 418 (2006) p. 282.

[3] T. Baskaran and Shashi Bhushan Arya, Ceram. Int, 44 (2018) p. 17695.
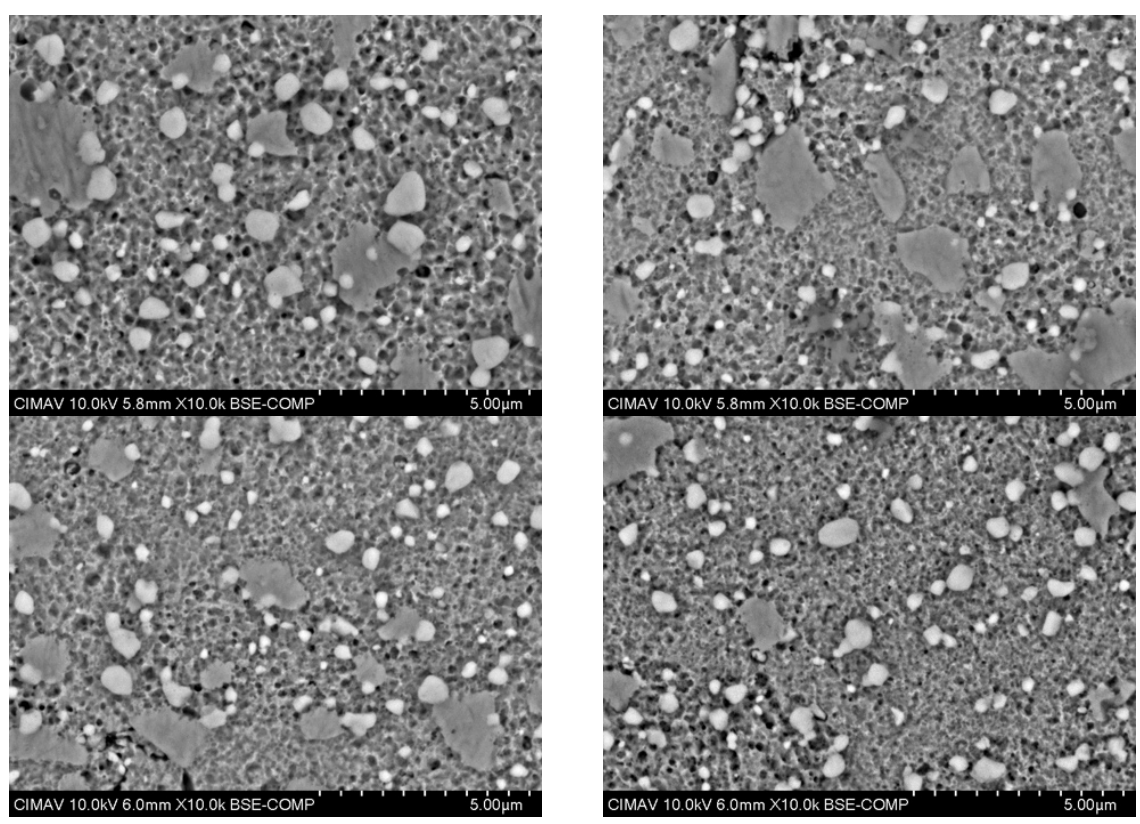

Figure 1. SEM-BSE Micrographs of Inconel 718 and those with Ce/La additions in sintered condition. a) Inconel $718, \mathrm{~b}), \mathrm{c}$ ) and d) with $0.1,0.2$ and $0.3 \mathrm{Ce} / \mathrm{La}$ (wt. \%), respectively.

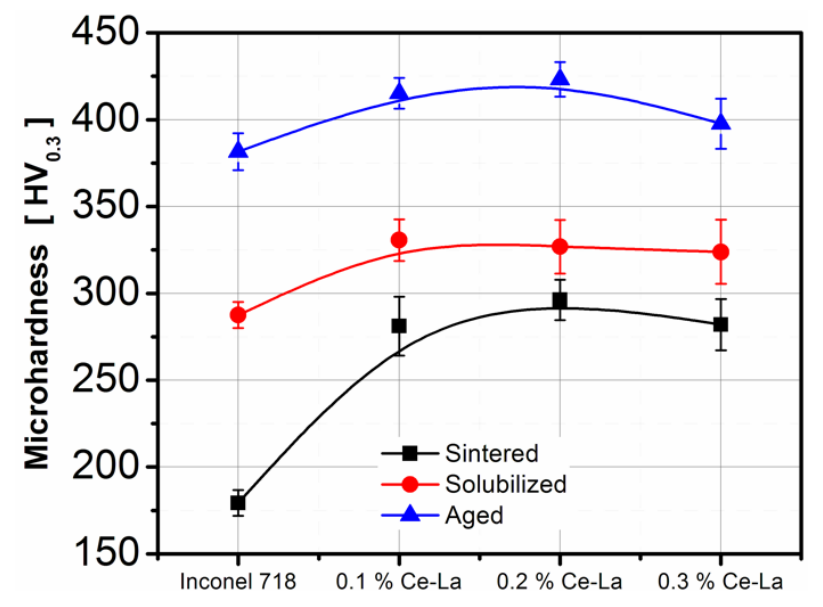

Figure 2. Vickers microhardness versus Inconel 718 and those modified with Ce/La additions, after sintered, solubilized and aged conditions. 